\title{
Two first cousins with spondyloepiphyseal dysplasia tarda (X linked recessive form), one also with poikiloderma atrophicans vasculare progressing to lymphocytic lymphoma
}

\author{
WILLIAM A BRANFORD, GEORGE W BEVERIDGE, AND \\ RUTH WYNNE-DAVIES
}

From the Department of Dermatology, The Royal Infirmary, Edinburgh, and the
Department of Orthopaedic Surgery, University of Edinburgh, Edinburgh

SUMMARY Two male cousins with spondyloepiphyseal dysplasia tarda ( $X$ linked recessive form) are described. One presented with a poorly differentiated lymphocytic lymphoma of the skin in areas of poikiloderma atrophicans vasculare which had been present for 10 years.

\section{Case reports}

The index patient first presented in 1970 at the age of 15 years with a non-itching eruption of 2 years' duration on his left shoulder, left costal margin, and left thigh. The skin in these areas was dry, scaly, and atrophic, with prominent telangiectasia and a reticulate background of pigmentation. The histology was consistent with the diagnosis of poikiloderma atrophicans vasculare, although there was extension of the lymphohistiocytic infiltrate into the deep dermis. No treatment was advised but he was followed up for one year before defaulting.

In 1977 he returned to hospital with an acute perforation of a duodenal ulcer. Two years later (aged 22 years), pinkish nodules up to $1 \mathrm{~cm}$ in diameter were noticed in the original area of poikiloderma on his left shoulder and several infiltrated lesions which were showing signs of ulceration were present on a deeply pigmented patch on his right buttock. Large, firm, mobile lymph nodes were palpable in both groins but there was no hepatosplenomegaly.

Haematological studies showed: haemoglobin $15.8 \mathrm{~g} / \mathrm{dl}$, white blood cell count $7.6 \times 10^{9} / 1$ with $50 \%$ neutrophils, $41 \%$ lymphocytes, $8 \%$ monocytes, and $1 \%$ eosinophils. Platelet count was $215 \times 10^{9} / 1$ and ESR $6 \mathrm{~mm}$ in the first hour. Bone marrow examination was normal and his marrow cells had the normal male karyotype. The following investigations were also normal: blood urea and electrolytes, liver function tests, serum calcium, phosphate, Received for publication 18 July 1981 thyroxine, cholesterol, proteins, immunoglobulins, $\vec{\oplus}$ and components $\mathrm{CH} 50, \mathrm{C} 3$, and $\mathrm{C} 4$. Urine contained $\stackrel{\infty}{\sim}$ no abnormal amino-acids. Bilateral ascending lymphangiography demonstrated abnormal pelvic and para-aortic lymph nodes. Biopsy of one of the shoulder nodules showed a dense, mainly lymphocytic, infiltrate extending into the deep dermis. The $\frac{}{\mathbb{D}}$ features were those of a poorly differentiated $\stackrel{\varrho}{\Rightarrow}$ lymphocytic lymphoma rather than classical mycosis fungoides, with which poikiloderma atrophicans vasculare is more usually associated. Cytochemistry was attempted but the cell yield was too small for this to be helpful.

Histological examination of an excised node and receptor studies suggested simple follicular hyperplasia. Dermatopathic lymphadenopathy was also thought to be responsible for the abnormal intraabdominal nodes seen on lymphangiography. Investigations did not therefore reveal any definite evidence of a systemic lymphoma.

Diagnosis of the $X$ linked recessive form of spondyloepiphyseal dysplasia tarda was only $N^{\circ}$ established at the age of 23 years on the basis of late $N$ onset of locomotor symptoms, body proportions, N radiographic changes, and pedigree (fig 1).

He was $159 \mathrm{~cm}$ tall with a head to pubis measurement of $76 \mathrm{~cm}$ and pubis to heel measurement of $83 \mathrm{~cm}$, indicating only slight shortness of stature associated with a short trunk (fig 2). His span was? normal at $203 \mathrm{~cm}$. There was some stiffness of the spine, but movements at all other joints except the $\underset{\mathbb{D}}{\stackrel{\circ}{ }}$ hips were normal, and these only lacked external $\frac{\rho}{\circ}$ rotation. Radiographs illustrated platyspondyly of $\stackrel{0}{\circ}$ 


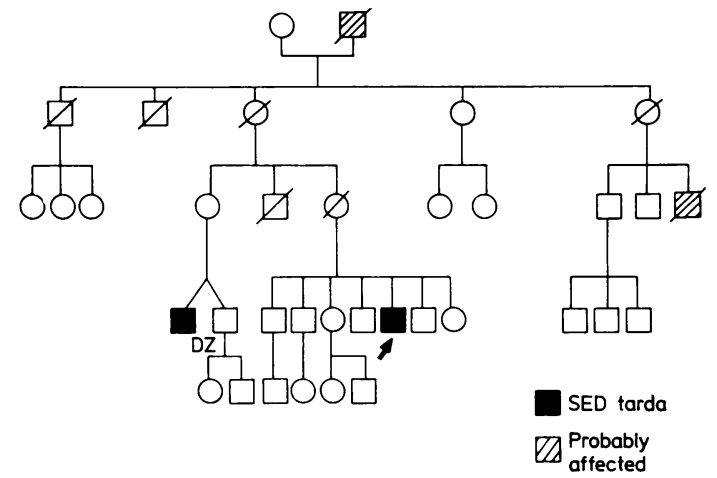

FIG 1 Pedigree of the family.

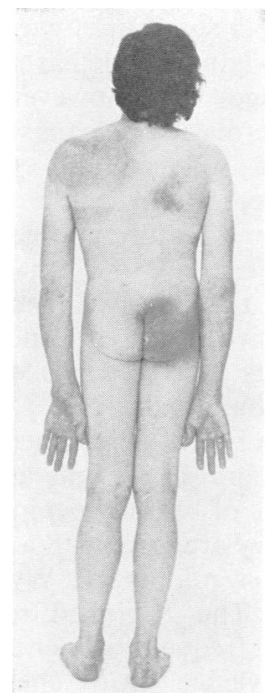

FIG 2 Index patient aged 23 years: height $159 \mathrm{~cm}$ with short trunk, normal limbs, and ulceration of the tumour nodules on the right buttock patch of poikiloderma.

most vertebrae (fig 3) and the femoral heads were flattened and irregular. There was a bifid seventh rib on the left, but no other findings of note.

A male first cousin on the maternal side, now aged 30 years, was similarly affected, with a height of $149.9 \mathrm{~cm}$, head to pubis measurement of $67.3 \mathrm{~cm}$, and pubis to heel measurement of $82.6 \mathrm{~cm}$ (fig 4). His short stature was not noted until the age of 10 years and back pain only occurred at 27 years. He lacked some external rotation at the hips, but other joints moved freely. There was no previous history nor sign of any skin disorder. Radiographs confirmed the typical appearance of the vertebrae (fig 5) and showed some irregularity of the femoral heads with early osteoarthritis (fig 6). There were no significant radiographic findings elsewhere.

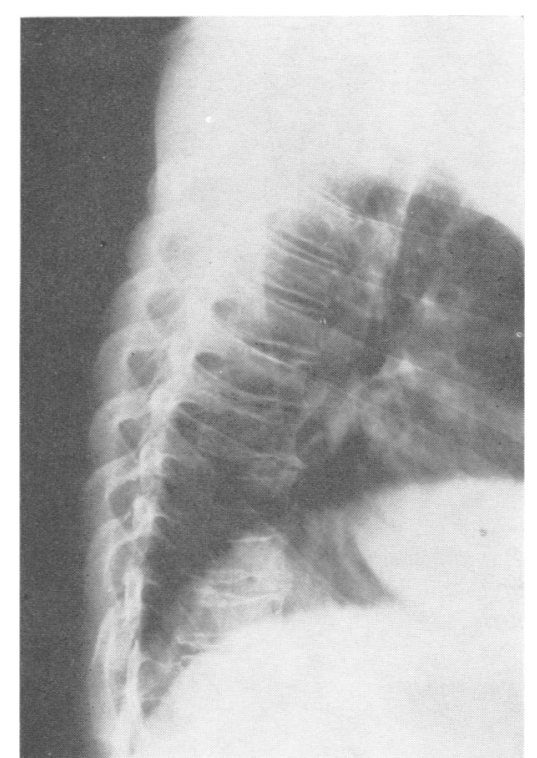

FIG 3 Lateral radiograph of spine with flattening and irregularity of vertebral bodies and hump shaped protrusions from superior and inferior surfaces.

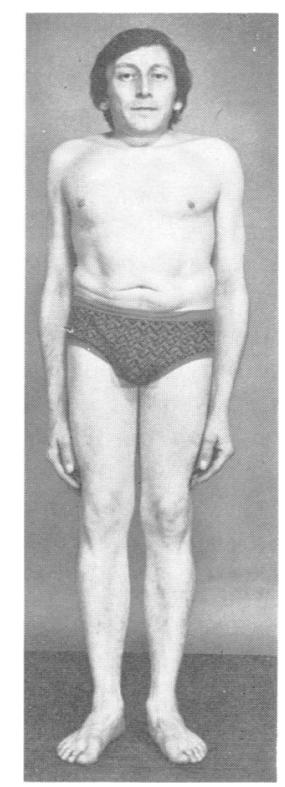

FIG 4 First cousin of index patient, aged 30 years: height $149.9 \mathrm{~cm}$ with short trunk and normal limbs. 


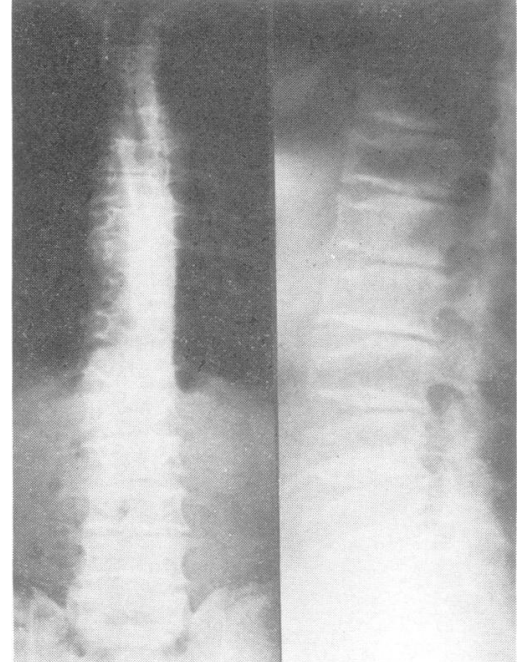

FIG $5 A P$ and lateral radiographs of spine with platyspondyly and hump shaped protrusions superiorly and inferiorly.

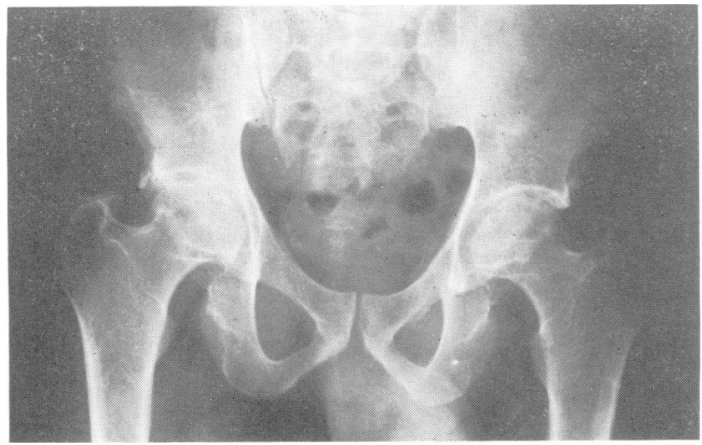

FIG 6 AP radiograph of pelvis with some irregularity of femoral heads and early osteoarthritis.

Two more distant male relatives were thought to be affected with spondyloepiphyseal dysplasia tarda (a great grandfather and a first cousin once removed) but both were dead and there was no confirmatory medical evidence. There was no evidence for skin or skeletal disorders in any other member of the family, nor any other developmental anomalies of note.

\section{Discussion}

Poikiloderma is characterised by atrophy, a reticulate variation in pigmentation, and telangiectasia. It may be a local response to skin injury from cold, heat, ionising radiation, or photosensitising chemicals. Rarely it occurs as a manifestation of dermatomyositis, lupus erythematosus, or scleroderma, but the distribution is then different. Poikiloderma can $\stackrel{\mathbb{D}}{\stackrel{D}{(1)}}$ be the precursor of cutaneous lymphoma and this is usually seen in patients with poikiloderma $\overrightarrow{\vec{F}}$ atrophicans vasculare or the premalignant type of parapsoriasis en plaques. Poikiloderma atrophicans $\frac{C}{0}$ vasculare seldom develops before middle age $\frac{\bar{c}}{\bar{\alpha}}$ although 24 of the 122 cases $(19.7 \%)$ reported by $\widehat{\Phi}$ Samman ${ }^{1}$ were aged 20 or under at the onset of the disease. The condition is extremely rare, representing $\omega$ only $0.015 \%$ of new patients seen at St John's $\vec{O}$ Hospital, London, during 1952 to $1965 .^{2}$

Poikiloderma or poikiloderma-like eruptions $\vec{\omega}$ occur at an early age in several inherited conditions. $^{34}$ In some of these the resemblance to 0 premalignant poikiloderma is not marked and $\overrightarrow{0}$ lymphomatous transformation does not occur, $\dot{\omega}$ although interestingly congenital telangiectatic $N$ erythema (Bloom's syndrome) carries an increased risk of systemic lymphoreticular malignancy. The 의 histological changes may, however, be identical to $\overrightarrow{-}$ those of poikiloderma atrophicans vasculare as found $\subseteq$ in poikiloderma congenitale, the Rothmund- $\widehat{\Phi}$ Thomson syndrome. ${ }^{5}$ In these children photo- $\overrightarrow{0}$ sensitivity is often a feature and epitheliomata may develop in later life.

It seems likely that the two men suffer from the $\mathrm{X}$ linked recessive form of spondyloepiphyseal dysplasia tarda as described by Maroteaux et al, ${ }^{6}$ Langer, ${ }^{7}$ and Bannerman et al. ${ }^{8}$ The pedigree is $\stackrel{\circ}{\otimes}$ consistent with this pattern of inheritance, and their clinical and radiographical signs are typical. There $\overrightarrow{\overrightarrow{0}}$ are several types of spondyloepiphyseal dysplasia but as a group they are rare, with a likely prevalence of around 7.7 per million ( $R$ Wynne-Davies, unpublished data). The $X$ linked recessive form is probably the most frequently diagnosed.

To our knowledge skin changes have not previously been reported in this condition, but it is felt that the rarity of the two disorders would make their coincidental appearance in the same patient extremely unlikely.

We wish to thank the medical illustration services of the Royal Infirmary and Edinburgh University for the photographs and Mrs Seatter for her secretarial o assistance.

\section{References}

1 Samman PD. Mycosis fungoides and other cutaneous reticuloses. Clin Exp Dermatol 1976;1:197-214.

2 Neves H. Incidence of skin diseases 1952-65. Trans St $\mathbb{D}$ Johns Hosp Dermatol Soc 1966;52:255-71.

3 Weary PE, Hsu HY, Richardson DR, Caravati CM, T Wood BT. Hereditary sclerosing poikiloderma. Arch Dermatol 1969;100:413-22.

${ }^{4}$ Rook A. Genetics in dermatology. In: Textbook of dermatology. 3rd ed, vol 1. Oxford: Blackwell, 1979: 97-139. 
5 Lever WF, Schaumberg-Lever G. Histopathology of the skin. 5th ed. Philadelphia: Lippincott, 1975:68-9.

6 Maroteaux P, Lamy M, Bernard J. La dysplasie spondyloepiphysaire tardive. Presse Med 1957;65:1205-8.

7 Langer LO. Spondyloepiphyseal dysplasia tarda. Hereditary chondrodysplasia with characteristic vertebral configuration in the adult. Radiology 1964;82:833-9.

8 Bannerman RM, Ingall GB, Mohn JF. X-linked spondyloepiphyseal dysplasia tarda: clinical and linkage data. J Med Genet 1971 ;8:291-301.

Requests for reprints to Dr G W Beveridge, Department of Dermatology, The Royal Infirmary, Edinburgh EH3 9YW. 